\title{
Life Cycle Exergy Analysis of Renewable Energy Systems
}

\author{
Göran Wall*
}

Department of Culture, Energy and Environment University of Gotland Cramérgatan 3, SE-621 67, Visby, Sweden

\begin{abstract}
Exergy concepts and exergy based methods offer an insight to the understanding of sustainable energy engineering. The utilization of energy and other resources by applying physical concept as exergy and exergy based methods and the value of these tools in the design are presented, in particular Life Cycle Exergy Analysis (LCEA). LCEA is applied to a typical wind power plant. This brings a new approach and insight to the engineering conditions for a sustainable development that is further elaborated. The importance of introducing this new knowledge into present engineering education and practices is argued for.
\end{abstract}

Keywords: Life cycle analysis, exergy, wind power.

\section{INTRODUCTION}

Exergy is a suitable scientific concept in the work towards sustainable development. Exergy accounting of the use of energy and material resources provides important knowledge on how effective and balanced a society is in the matter of conserving nature's capital. This knowledge can identify areas in which technical and other improvements should be undertaken, and indicate the priorities, which should be assigned to conservation measures, efficiency improvements and optimizations. Thus, exergy concept and tools are essential to the creation of a new engineering paradigm towards sustainable development.

\section{EXERGY}

The exergy concept originates from works of Carnot [1], Gibbs [2], Rant [3] and Tribus [4] and the history is well documented [5]. Exergy of a system is $[6,7]$

$$
\mathrm{E}=\mathrm{U}+\mathrm{P}_{0} \mathrm{~V}-\mathrm{T}_{0} \mathrm{~S}-\sum_{\mathrm{i}} \mu_{\mathrm{i} 0} \mathrm{n}_{\mathrm{i}}
$$

where $U, V, S$, and $n_{i}$ denote extensive parameters of the system (energy, volume, entropy, and the number of moles of different chemical materials $i$ ) and $P_{0}, T_{0}$, and $\mu_{i 0}$ are intensive parameters of the environment (pressure, temperature, and chemical potential). Analogously, the exergy of a flow can be written as:

$$
\mathrm{E}=\mathrm{H}-\mathrm{T}_{0} \mathrm{~S}-\sum_{\mathrm{i}} \mu_{\mathrm{i} 0} \mathrm{n}_{\mathrm{i}}
$$

where $H$ is the enthalpy.

All processes involve the conversion and spending of exergy, thus high efficiency is of utmost importance. This implies that the exergy use is well managed and that effective tools are applied. Presently, an excellent online web

\footnotetext{
*Address correspondence to this author at the Department of Culture, Energy and Environment University of Gotland Cramérgatan 3, SE-621 67, Visby, Sweden; Tel: +46 (0) 498299131; Fax: +46 (0) 498299962;

E-mail: gw@exergy.se
}

tool for calculating exergy of chemical substance is also available [8].

Energy is always in balance, however, for real processes exergy is never in balance due to irreversibilities, i.e. exergy destruction that is related to the entropy production by

$\mathrm{E}_{\text {in }}^{\text {tot }}-\mathrm{E}_{\text {out }}^{\text {tot }}=\mathrm{T}_{0} \Delta \mathrm{S}^{\mathrm{tot}}=\sum_{\mathrm{i}}\left(\mathrm{E}_{\mathrm{in}}-\mathrm{E}_{\text {out }}\right)_{\mathrm{i}}>0$

where $\Delta S^{\text {tot }}$ is the total entropy increase, $E_{\text {in }}^{\text {tot }}$ is the total exergy input, $E_{\text {out }}^{\text {tot }}$ is the total exergy output, and $\left(\mathrm{E}_{\text {in }}-\mathrm{E}_{\text {out }}\right)_{\mathrm{i}}$ is the exergy destruction in process $i$.

The exergy loss, i.e. destruction and waste, indicates possible process improvements. In general "tackle the biggest loss first" approach is not always appropriate since every part of the system depends on each other, so that an improvement in one part may cause increased losses in other parts. As such, the total losses in the modified process may in fact be equal or even larger, than in the original process configuration. Also, the use of renewable and non-renewable resources must be considered. Therefore, the problem needs a more careful approach.

\section{EXERGY ANALYSIS}

In engineering, flow diagrams are often used to describe the energy or exergy flows through a process. Fig. (1) shows a typical thermal power station, its main components and roughly the main energy and exergy flows of the plant. This diagram shows where the main energy and exergy losses occur in the process, and also whether exergy is destroyed from irreversibilities or whether it is emitted as waste to the environment. In the energy flow diagram energy is always conserved, the waste heat carries the largest amount of energy into the environment, far more than is carried by the exhaust gases. However, in the exergy flow diagram the temperature of the waste heat is close to ambient so the exergy becomes much less. The exergy of the exhaust gas and the waste heat are comparable. 

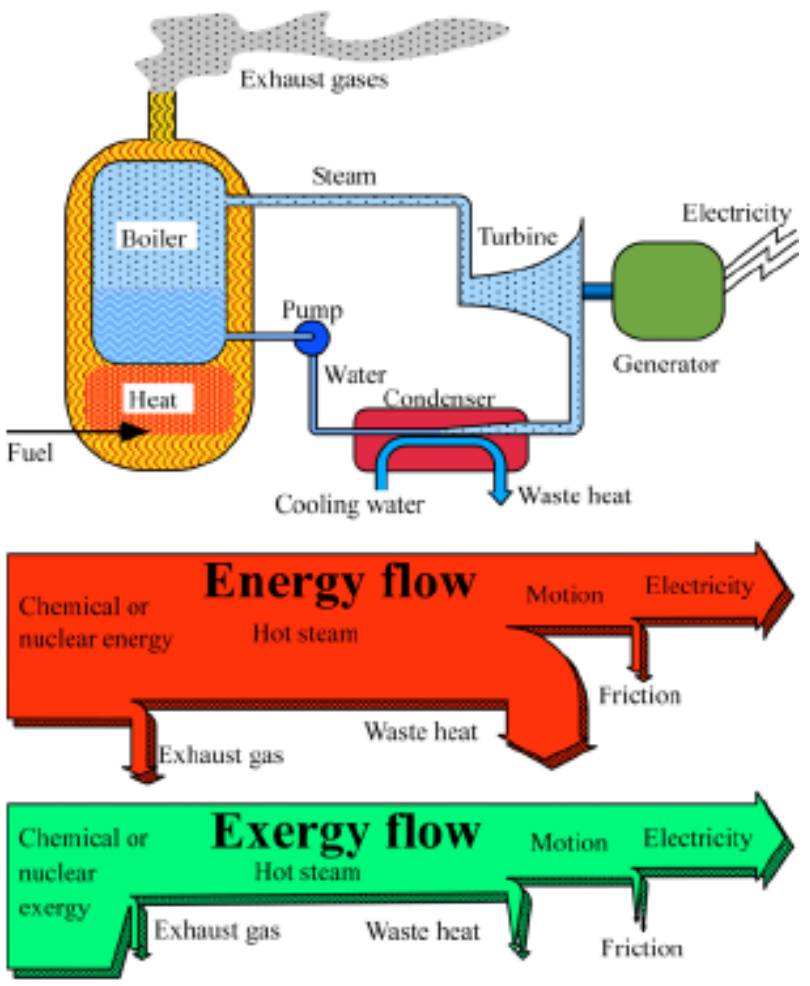

Fig. (1). Energy and exergy flow of a thermal power plant.

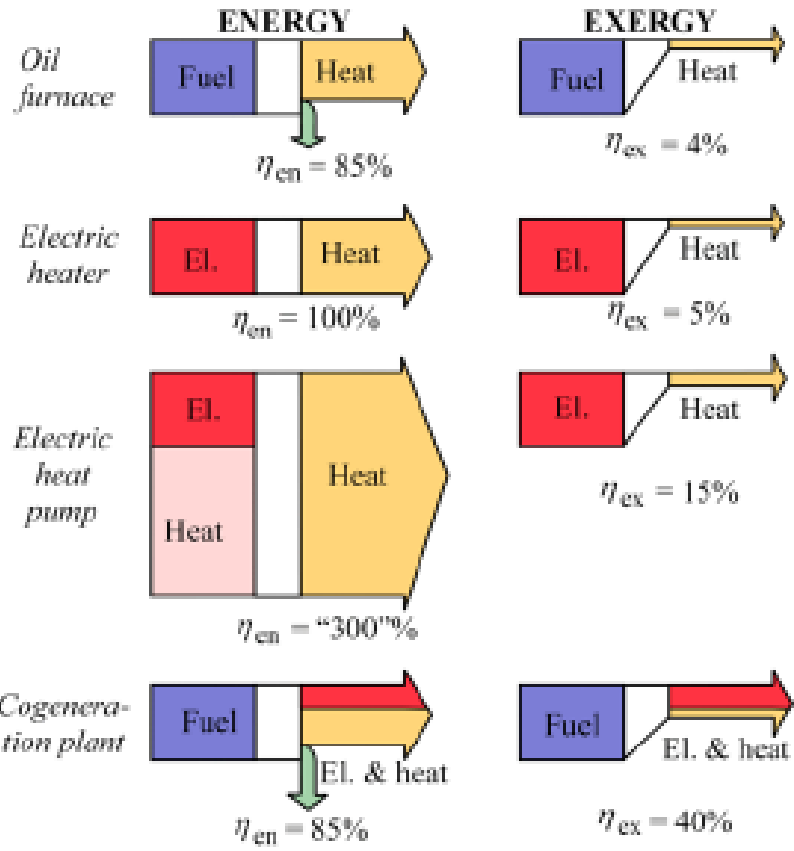

Fig. (2). Energy and exergy flows through typical some energy systems [6].

Fig. (2) illustrates the energy and exergy flows of an oil furnace, an electric heater, an electric heat pump and a combined power and heat plant, i.e. a cogeneration plant. The produced heat is used for space heating. In the oil furnace the energy efficiency is assumed to be typically about $85 \%$, losses being due mainly to the hot exhaust gases. The exergy efficiency is very low, about $4 \%$, because the temperature difference is not utilized when the temperature

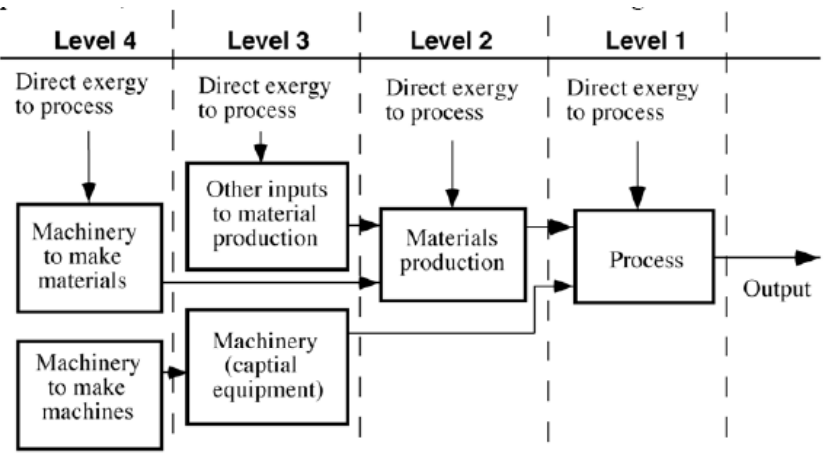

Fig. (3). Levels of an exergy process analysis.

is decreased, to a low of about $20^{\circ} \mathrm{C}$, as a comfortable indoor climate.

Electric heating by short-circuiting in electric resistors has an energy efficiency of $100 \%$, by definition of energy conservation. The energy efficiency of an electric heat pump is not limited to $100 \%$. If the heat originating from the environment is ignored in the calculation of the efficiency, the conversion of electrical energy into indoor heat can be well over $100 \%$, e.g. $300 \%$ as in Fig. (2). The exergy flow diagram of the heat pump looks quite different. The exergy efficiency for an electric heater is about $5 \%$ and for the heat pump, $15 \%$.

In Fig. (1) the energy and exergy efficiencies are the same because for the inflow of fuels and the outflow of electricity both energy and exergy is almost equal. For a combined power and heat plant, i.e. a cogeneration plant (Fig. 2) the exergy efficiency is about the same as for a thermal power plant (Fig. 1). This can be better understood from the exergy diagrams. The main exergy loss occurs in the conversion of fuel into heat in the boiler. Since this conversion is practically the same in both the condensing and the combined power plants, the total exergy efficiency will be the same, i.e. about $40 \%$. However, it may be noted that the power that is instead converted into heat corresponds to a heat pump with a coefficient of performance (COP) of about 10. Thus, if there is a heating need a cogeneration plant is far superior to a condensing power plant. The maximum energy efficiency of an ideal conversion process may be over $100 \%$, depending on the definition of efficiency. The exergy efficiency, however, can never exceed $100 \%$.

\section{LIFE CYCLE EXERGY ANALYSIS}

To estimate the total exergy input that is used in a production process it is necessary to take all the different inflows of exergy to the process into account. This type of budgeting is often termed Exergy Analysis [6, 7], Exergy Process Analysis, see Fig. (3), or Cumulative Exergy Consumption [9], and focuses on a particular process or sequence of processes for making a specific final commodity or service. It evaluates the total exergy use by summing the contributions from all the individual inputs, in a more or less detailed description of the production chain.

Environmentally oriented Life Cycle Analysis or Assessment (LCA) are common to analyze environmental problems associated with the production, use and disposal or recycling of products or product systems, see Fig. (4). Every 


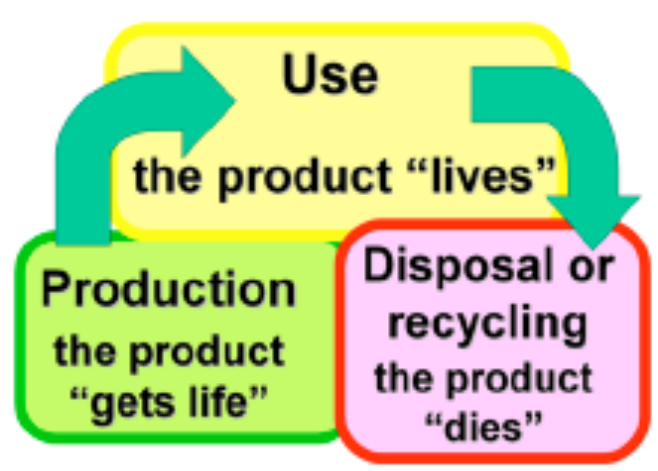

Fig. (4). The life cycle "from cradle to grave".

product is assumed to be divided into these three "life processes", or as it is sometimes named "from cradle to grave".

For every "life process" the total inflow and outflow of energy and material is computed, thus, LCA is similar to Exergy Analysis. In general Exergy Analysis and LCA have been developed separately even though they are strongly linked. This inventory of energy and material balances is then put into a framework as described in Fig. (5). Four stages in the LCA can be distinguished: (1) Objectives and boundaries, (2) Inventory, (3) Environmental impact, and (4) Measures. These four main parts of an LCA are indicated by boxes, and the procedure is shown by arrows. Green arrows show the basic steps and red arrows indicate suitable next steps, in order to further improve the analysis.

In LCA the environmental burdens are associated with a product, process, or activity by identifying and quantifying energy and materials used, and wastes released to the environment. Secondly one must assess the impact on the environment, of those energy and material uses and releases. Thus it is divided into several steps (Fig. 4).

The multidimensional approach of LCA causes large problems when it comes to comparing different substances, and general agreements are crucial. This problem is avoided if exergy is used as a common quantity, which is done in Life Cycle Exergy Analysis (LCEA) [10].

In this method we distinguish between renewable and non renewable resources. The total exergy use over time is also considered. These kinds of analyses are of importance in order to develop sustainable supply systems of exergy in society. The exergy flow through a supply system, such as a power plant, usually consists of three separate stages over time (Fig. 6). At first, we have the construction stage where exergy is used to build a plant and put it into operation. During this time, $0 \leq t \leq t_{\text {start }}$, exergy is spent of which some is accumulated or stored in materials, e.g. in metals etc. Secondly we have the maintenance of the system during time of operation, and finally the clean up stage. These time periods are analogous to the three steps of the life cycle of a product in an LCA. The exergy input used for construction, maintenance and clean up we call indirect exergy $E_{\text {indirect }}$ and we assume this originates from non renewable resources. When a power plant is put into operation, it starts to deliver a product, e.g. electricity with exergy power $\dot{\mathrm{E}}_{\mathrm{pr}}$, by converting the direct exergy power input $\dot{E}_{\text {in }}$ into demanded energy forms, e.g. electricity. In Fig. (6) the direct exergy is a non-

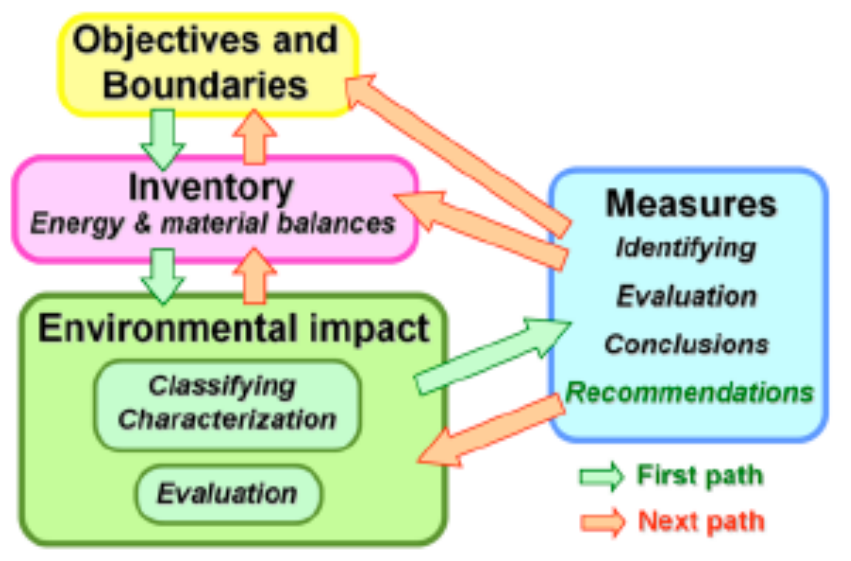

Fig. (5). Main steps of a LCA.

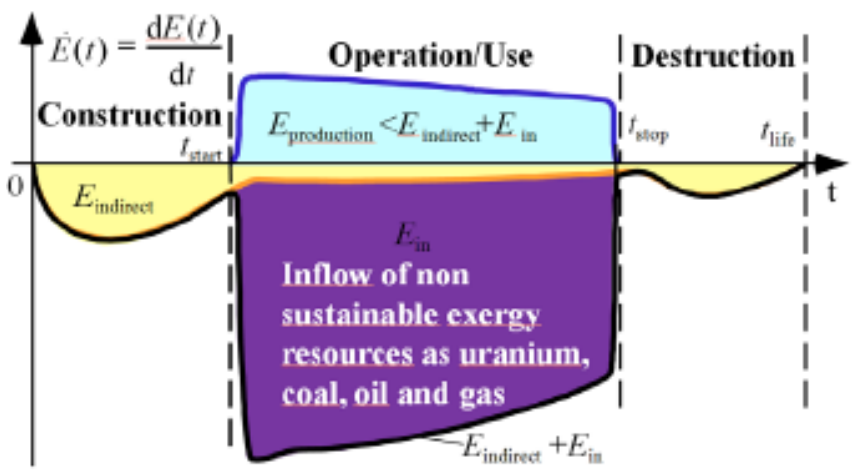

Fig. (6). LCEA of a fossil fueled power plant.

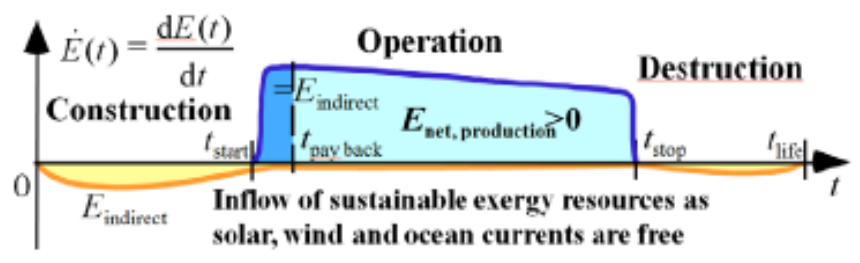

Fig. (7). LCEA of a wind power plant.

renewable resource, e.g. fossil fuel and in Fig. (7) the direct exergy is a renewable resource, e.g. wind.

In the first case, the system is not sustainable, since we use exergy originating from a non-sustainable resource. We will never reach a situation where the total exergy input will be paid back, simply because the situation is powered by a depletion of resources, we have $E_{\mathrm{pr}}<E_{\text {in }}+E_{\text {indirect. }}$. In the second case, instead, at time $t=t_{\text {payback }}$ the produced exergy that originates from a natural flow has compensated for the indirect exergy input, see Fig. (7), i.e.

$$
\int_{t_{\text {satart }}}^{t_{\text {pay back }}} \dot{\mathrm{E}}_{\mathrm{pr}}(\mathrm{t}) \mathrm{dt}=\int_{0}^{\mathrm{t}_{\text {tirie }}} \dot{\mathrm{E}}_{\text {indirect }}(\mathrm{t}) \mathrm{dt}=\mathrm{E}_{\text {indirect }}
$$

Since the exergy input originates from a renewable resource we may not account for it. By regarding renewable resources as free then after $t=t_{\text {payback }}$ there will be a net exergy output from the plant, which will continue until it is closed down, at $t=t_{\text {close }}$. Then, exergy has to be used to clean up and restore the environment, which accounts for the last 

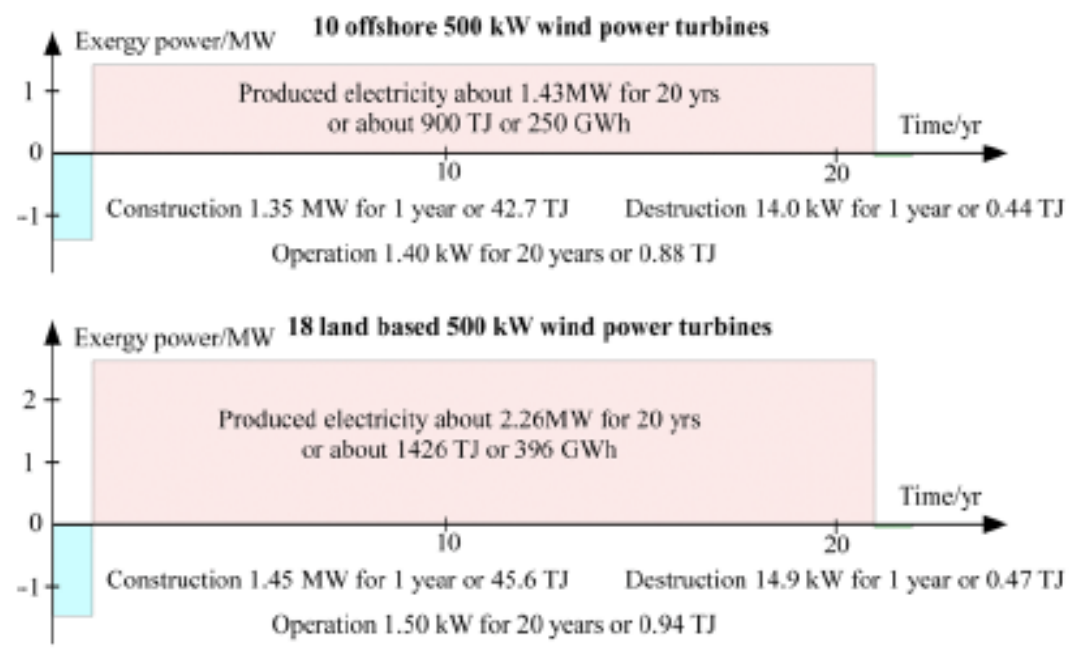

Fig. (8). LCEA of an offshore wind power farm and a land based farm.

part of the indirect exergy input, i.e., $E_{\text {indirect }}$, which is already accounted for (Eq. 8). By considering the total life cycle of the plant the net produced exergy becomes $E_{\text {net,pr }}=E_{\mathrm{pr}}-E_{\text {indirect }}$. These areas representing exergies are indicated in Fig. (7). Assume that, at time $t=0$, the production of a wind power plant starts and at time $t=t_{\text {start }}$ it is completed and put into operation. At that time, a large amount of exergy has been used in the construction of the plant, which is indicated by the area of $E_{\text {indirect }}$ between $t=0$ and $t=t_{\text {start }}$ Then the plant starts to produce electricity, which is indicated in Fig. (7) by the upper curve $E_{\mathrm{pr}}=E_{\text {indirect }}+E_{\text {net,pr. }}$. At $t=t_{\text {payback }}$ the exergy used for construction, maintenance and clean up has been paid back. For modern wind power plants this time is only some months. Then the system has a net output of exergy until it is closed down, which for a wind power station may last for decades. Thus, these diagrams could be used to show if a power supply system is sustainable.

LCEA is very important in the design of sustainable systems, especially in the design of renewable energy systems. Take a solar panel, made of mainly aluminum and glass that is used for the production of hot water for household use, i.e. about $50^{\circ} \mathrm{C}$. Then, it is not obvious that the exergy being spent in the production of this unit ever will be paid back during its use, i.e., it might be a misuse of resources rather than a sustainable resource use. The production of aluminum and glass require a lot of exergy as electricity and high temperature heat or several hundred degrees Celsius, whereas the solar panel delivers small amounts of exergy as low temperature heat. LCEA must therefore be carried out as a natural part of the design of sustainable systems in order to avoid this kind of misuse. Another case to investigate is the production of biofuels in order to replace fossil fuels in the transport sector. This may not necessarily be sustainable since the production process uses a large amount of fossil fuels, directly for machinery or indirectly as fertilizers, irrigation and pesticides. This will be well described by a LCEA.

Sustainable engineering could be defined as systems which make use of renewable resources in such a way that the input of non-renewable resources will be paid back during its life time, i.e. $E_{\mathrm{pr}}>E_{\mathrm{in}}+E_{\text {indirect. }}$ In order to be truly sustainable the used deposits must also be completely restored or, even better, not used at all. Thus, by using LCEA and distinguishing between renewable and non-renewable resources we have an operational method to define sustainable engineering.

LCEA diagrams are of particular importance in the planning of large scale renewable energy systems of multiple plants. Initially, this system will consume most of its supply within its own constructions phase. However, some time after completion it will deliver at full capacity. Thus, the energy supply over time is heavily affected by internal system dynamics.

\section{LCEA APPLIED TO TYPICAL WIND POWER SYSTEMS}

There are numerous publications on life cycle analysis of different wind power systems. The energy use for construction, operation and destruction are often presented. Schleisner [11] analyzed energy and emissions of the production and manufacturing of materials for an offshore and land based wind farm. The offshore wind farm consisted of 10 units of $500 \mathrm{~kW}$ turbines or $5 \mathrm{MW}$ and a land based wind farm 18 of $500 \mathrm{~kW}$ or $9 \mathrm{MW}$. The primary energies used in the production and disposal of materials amount to about 44 and $47 \mathrm{TJ}$ for the offshore and land based farm respectively. With yearly electricity production of about 45 and $71 \mathrm{TJ}$ this imply about 1 and 0.7 years payback time respectively. Assume that the construction accounts for $97 \%$, operation for $1 \%$ and deconstruction for $2 \%$ of the total exergy input and that construction and deconstruction last for one year each then we will have the following LCEA diagram for a life time of 20 years, see Fig. (8).

We see that the total exergy input is minor to the produced electrical exergy and the exergy input for operation and deconstruction is hardly visible. Thus, the LCEA shows that this wind power system is truly sustainable.

In a study for Taiwan the lifecycle stages of a planned land based wind turbine farm of three different turbines are analyzed [12]. Three turbines are investigated Vestas (V-47), Enercon (E-40), and Vestas (V-66), see Table 1. The turbine manufacturing, foundation construction, as well as operation and disposal of the wind power systems are considered. 


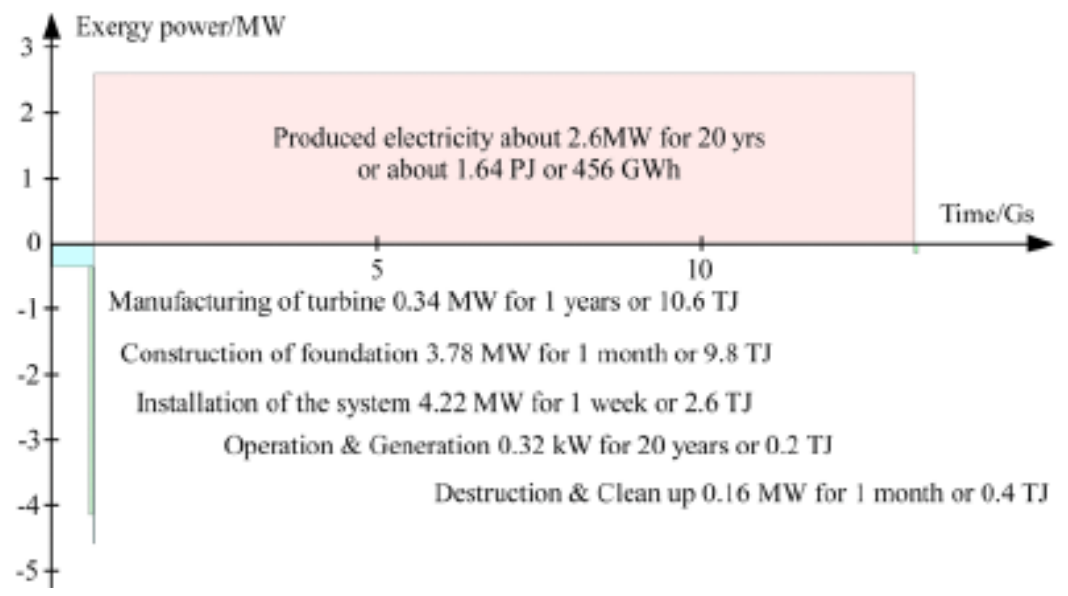

Fig. (9). LCEA of a wind power plant.

Table 1. Lifecycle Inventory of Energy Input of Three Demo Wind Power Systems

\begin{tabular}{|c|c|c|c|}
\hline Energy Input (GJ) & $\begin{array}{c}\text { Vestas (V- } \\
\mathbf{4 7})\end{array}$ & $\begin{array}{c}\text { Enercon (E- } \\
\mathbf{4 0 )}\end{array}$ & $\begin{array}{c}\text { Vestas (V- } \\
\mathbf{6 6})\end{array}$ \\
\hline \hline $\begin{array}{c}\text { Manufacturing of } \\
\text { turbine }\end{array}$ & 3,486 & 3,202 & 3,898 \\
\hline $\begin{array}{c}\text { Construction of } \\
\text { foundation }\end{array}$ & 3,226 & 2,964 & 3,608 \\
\hline $\begin{array}{c}\text { Installation of the } \\
\text { system }\end{array}$ & 847 & 827 & 877 \\
\hline $\begin{array}{c}\text { Operation \& gen- } \\
\text { eration }\end{array}$ & 67 & 62 & 75 \\
\hline $\begin{array}{c}\text { Destruction \& clean } \\
\text { up }\end{array}$ & 134 & 123 & 150 \\
\hline Total energy input & 23,547 & & \\
\hline $\begin{array}{c}\text { Total electricity } \\
\text { generated }\end{array}$ & $1,640,670$ & & \\
\hline
\end{tabular}

From these data we can set up an LCEA by assuming that the energy input can be regarded as exergy since the energy originates mostly from fuels and electricity, see Fig. (9).

In this case we see that construction of foundation and installation of the system accounts for high exergy power input in the final state of construction. However, as before the total exergy input is paid back in only a few months by the produced electrical exergy.

\section{CONCLUSIONS}

Exergy is an excellent concept to describe the utilization of energy and material resources in systems. The combination of LCA with exergy and distinguish between non renewable and renewable resources to form LCEA offers a unique efficient method to analyze the level of sustainability for energy systems. The application of LCEA to different wind power systems gives an excellent visualization of the exergy flows involved. Thus, in these cases it becomes obvious that the exergy input is well paid back and that the systems will be net producers of exergy. LCEA is strongly recommended as a suitable tool in the analysis of level of sustainability for energy systems and should be part of every energy engineering curricula.

\section{ACKNOWLEDGEMENTS}

The permission to use my work for the UNESCO's Encyclopedia of Life Support Systems [13] for this paper is hereby gratefully acknowledged.

\section{NOMENCALTURE}

E Exergy J

$\mathrm{E}_{\text {indirect }}$ Exergy indirect input $\mathrm{J}$

$\mathrm{E}_{\text {in }} \quad$ Exergy input $\quad J$

$\mathrm{E}_{\text {in }}$ Exergy power input W

$\mathrm{E}_{\text {out }} \quad$ Exergy output J

$\mathrm{E}_{\text {net,pr }} \quad$ Exergy net of product J

$\mathrm{E}_{\mathrm{pr}} \quad$ Exergy of product $\mathrm{J}$

$\mathrm{E}_{\mathrm{pr}} \quad$ Exergy power of product W

$\mathrm{E}^{\text {tot }} \quad$ Total exergy J

$\mathrm{E}_{\mathrm{tr}} \quad$ Transit exergy J

$\mathrm{E}_{\text {waste }} \quad$ Exergy of waste J

H Enthalpy J

$\mathrm{i}, \mathrm{j}, \mathrm{k}, 1 \quad$ Unit, $1,2, \ldots$

$\mathrm{P}_{0} \quad$ Pressure of the environment $\quad \mathrm{Pa}$

Q Heat (thermal energy in transit) J

S Entropy $\mathrm{J} \mathrm{K}^{-1}$

$S^{\text {tot }} \quad$ Entropy of the total system, i.e. the system and the environment $\mathrm{J} \mathrm{K}^{-1}$

t Time s

$\mathrm{t}_{0} \quad$ Time when a project starts, e.g. the first steps to build a power plant

$\mathrm{t}_{\text {close }} \quad$ Time when an operation closes, e.g. a power plant close down

$\mathrm{S}$

$\mathrm{t}_{\text {life }} \quad$ Time when a project finally closes, i.e. after complete restoration to original state

$\mathrm{S}$

$t_{\text {payback }} \quad$ Time when a payback situation is reached $s$

$\mathrm{t}_{\text {start }} \quad$ Time when an operation starts $\mathrm{s}$ 
$\mathrm{T}$

$\mathrm{T}_{0}$

$\mathrm{U}$

$\mathrm{V}$

$\mu_{i 0}$

Temperature

Temperature of the environment

Internal energy

Volume

Chemical potential of substance $i$ in its environmental state

$\mathrm{J} \mathrm{mol}^{-1}$

\section{REFERENCES}

[1] Carnot, S. Réflections sur la puisance motrice du feu et sur les machines propres a développer cette puissance. 1824, R. Fox, Paris: Bachelier, 1978.

[2] Gibbs, J.W. A Method of Geometrical Representation of the Thermodynamic Properties of Substances by Means of Surfaces. Trans. Conn. Acad., 1873, 2, 382-404.

[3] Rant, Z. Exergie, ein neues Wort für 'technische Arbeitsfähigkeit'. (Exergy, a New Word for Technical Available Work). Forschungen. Im. Ingenieurwesen., 1956, 22, 36-37.

[4] Tribus, M. Thermostatics and Thermodynamics. New York Van Nostrand, 1961. $\mathrm{J}$

$\mathrm{m}^{3}$
K [5] Sciubba, E.; Wall, G. A brief commented history of exergy from the beginnings to 2004 Int. J. Thermodyn., 2007, 10, 1-26.

K [6] Wall, G. Exergy — a Useful Concept within Resource Accounting, Report No. 77-42, Institute of Theoretical Physics, Göteborg, 1977. http://www.exergy.se/ftp/paper1.pdf

Wall, G. Exergy - a Useful Concept Ph.D. thesis, Chalmers University of Technology, Göteborg, Sweden, 1986. http://www.exergy.se/ftp/thesis.pdf

[8] The Exergoecological Portal, http://www.exergoecology.com

[9] Szargut, J; Morris, D. Cumulative exergy consumption. Energy Res., 1987, 11,245-61.

[10] Gong. M.; Wall. G, On Exergy and Sustainable Development Part 2: Indicators and methods. Int. J. Exergy., 2001, 1, 217-233.

[11] Schleisner, L. Life cycle assessment of a wind farm and related externalities. Renewable Energy, 2000, 20, 279-88.

[12] Lee, Y.M.; Tzeng, Y.E.; Su, C. Life Cycle Assessment of Wind Power Utilization in Taiwan. Institute of Natural Resource Management, National Taipei University, Taiwan http://www.ntpu.edu.tw/ads/doc/95/paper\%20su95.pdf

[13] EOLSS, Encyclopedia of Life Support Systems. www.eolss.net

(C) Göran Wall; Licensee Bentham Open.

This is an open access article licensed under the terms of the Creative Commons Attribution Non-Commercial License (http://creativecommons.org/licenses/by-nc/3.0/) which permits unrestricted, non-commercial use, distribution and reproduction in any medium, provided the work is properly cited. 